\title{
Weight Gain Associated with Chronic Exposure to Chlorpyrifos in Rats
}

\author{
William J. Meggs, MD, PhDa ${ }^{a}$ Kori L. Brewer, PhD ${ }^{a}$
}

aDepartment of Emergency Medicine, Brody School of Medicine, East Carolina University, Greenville, NC, 27858

\begin{abstract}
Objective: This work exposed rats to low levels of the organophosphate insecticide chlorpyrifos and monitored for toxic effects, including weight gain.

Methods: Rats received either a subcutaneous injection of chlorpyrifos, $5 \mathrm{mg} / \mathrm{kg} / \mathrm{day}$, or an equal volume of vehicle daily for 4 months. Subjects were observed for 30 minutes after injection for signs of acute toxicity. Body weights were recorded at baseline, 2 months, 3 months, and 4 months. At the end of the experiment, the weights of hearts, medial lobe of the livers, peri-nephric fat pads, and gastrocnemius muscles were recorded. Effects of chlorpyrifos on adipocyte differentiation in culture were studied. Results were compared using RMANOVA.

Results: No signs of acute cholinergic toxicity were observed after injections in any subject. Rats in the $5 \mathrm{mg} / \mathrm{kg}$ group were significantly heavier than those in the control group by 2 months $(335.7 \pm 16.7 \mathrm{~g}$ vs. $318.6 \pm 15.8 \mathrm{~g} ; \mathrm{p}=0.034)$. This difference increased at 3 months $(350.1 \pm 16.4 \mathrm{~g}$ vs. $322.3 \pm 21.3 \mathrm{~g} \mathrm{p}=0.006)$ and 4 months $(374.4 \pm 22.2 \mathrm{~g}$ vs. $340.2 \pm 25.2 \mathrm{~g} \mathrm{p}=0.006)$. At $4 \mathrm{months}$, the weights of the perinephric fat pads were significantly increased in the chlorpyrifos group relative to controls $(2.867+0.516$ vs. $1.130+0.171, \mathrm{p}=0.0039)$. The two groups showed no weight differences between hearts, livers, and gastrocnemius muscles. Chlorpyrifos did not affect adipocyte differentiation in tissue culture.

Conclusions: Chronic exposure to chlorpyrifos at $5 \mathrm{mg} / \mathrm{kg} /$ day caused an increase in rat body weight when compared to controls. This increase was in adipose tissue. Chlorpyrifos did not induce differentiation of adipocytes in culture.
\end{abstract}

\section{INTRODUCTION}

Obesity has increased in the United States over the past decade and affects children, adolescents, and adults. As many as $16.5 \%$ of children aged 6 to 19 years of age are classified as overweight, another $31.5 \%$ are considered at risk, and over $11 \%$ are obese $[1,2]$. Attributing the rapid and recent increase in obesity to overeating, inactivity, and genetics does not adequately explain the current trends [3]. A possible contributing cause is exposure to environment chemicals with biological activity.

Our population is chronically exposed to a host of environmental chemicals. Investigations by the Environmental Health
Laboratory at the Centers for Disease Control verify that human populations of the United States have detectable blood and urine levels of chemicals, including organophosphate insecticides [4]. Sources of exposure to these chemicals include residues on food and treatment of commercial and residential buildings for pest control.

Chronic exposure to organophosphate insecticides has been associated with neuropsychological conditions and has more recently been shown to have specific endocrine effects [5-7]. We are reporting the results of the effect of prolonged low-dose exposure to chlorpyrifos, an organophosphate insecticide, in young rats that gained weight. We did not observe any acute toxic

Keywords: chlorpyrifos, organophosphate compounds, obesity

Acknowledgements: The authors wish to thank Phillip Pekala, PhD, and his technical staff for assistance with the adipocyte assay. Notes: This work was supported by an American College of Medical Toxicology/Orphan Medical research grant.

Corresponding Author: William J. Meggs, MD, PhD, Department of Emergency Medicine, Brody School of Medicine at East Carolina University, 600 Moye Boulevard, Greenville, NC 27858. Email: meggsw@ecu.edu 
effects after dosing. Chlorpyrifos was chosen due to its history of extensive use and anecdotal reports of chronic problems after low level exposures in indoor settings. In addition, the effect on chlorpyrifos on adipocyte differentiation was assessed as a potential mechanism of the weight gain.

\section{METHODS}

The Institutional Animal Care and Use Committee of East Carolina University approved all experiments. This placebo controlled study used female Long-Evans rats about 6 months of age. Chlorpyrifos was obtained from SigmaAldrich (St. Louis, MO) and dissolved in DMSO then diluted with normal saline just prior to injection, for a final concentration of $4.0 \mathrm{mg} / \mathrm{mL}$. Each rat received daily subcutaneous injection of chorpyrifos, $5 \mathrm{mg} / \mathrm{kg} /$ day, $\mathrm{n}=10$, or an equal volume of vehicle $(n=10)$. Subjects were observed for 30 minutes after injection for signs of acute cholinergic or other toxicity, with atropine and pralidoxime available for treatment as needed. Expected and observed acute signs of toxicity in rats are fasciculations, muscle weakness, muscle paralysis, respiratory distress, seizures, coma, and moribund state. This protocol was carried out for 4 months. After the start of injections, weights were recorded at baseline, 2 months, 3 months, and 4 months. Weights were compared within each group using RMANOVA. Weights of two groups were compared at each time point using ANOVA followed by a Fisher PSD post-hoc analysis. A p-value of less than 0.05 was considered statistically significant. At the end of the study period, rats were euthanized by carbon dioxide inhalations. At necropsy, we removed and weighed hearts, livers, perinephric fat pads, and gastrocnemius muscles. 3T3-L1 preadipocytes were placed in cell culture and stimulated to differentiate using:

1) a mixture of methyl-isobutlylxantine (MIX), dexamethasone (DEX) and insulin (MDI; standard protocol);

2) $10 \mathrm{ul}$ of dimethyl sulphoxide (DMSO), or

3) increasing concentrations of chlorpyrifos $(.002 \mathrm{mg} / \mathrm{ml}$; $.004 \mathrm{mg} / \mathrm{ml} ; .006 \mathrm{mg} / \mathrm{ml}$ and $.008 \mathrm{mg} / \mathrm{ml}$ ) dissolved in 10 ul of DMSO. Cells from all groups were observed 24 hours and 6 days after stimulation, and descriptive findings of cell growth, fat accumulation, acceleration of growth, and number of cells are reported.

\section{RESULTS}

We did not observe any signs of acute cholinergic toxicity in any rat at any time after injection. One rat in the group that received $5 \mathrm{mg} / \mathrm{kg} /$ day of chlorpyrifos was euthanized during the second month of exposure due to the development of a mammary tumor, leaving a total of 9 animals in this group for analysis.

Both groups gained significant amounts of weight between baseline and 2 months $(\mathrm{p}<0.0001)$ as well as between 3 and 4 months. After exposure was initiated $(335.7 \pm 16.7 \mathrm{~g}$ vs. $318.6 \pm$ $15.8 \mathrm{~g} ; \mathrm{p}=0.034$ ), rats in the exposed group were significantly heavier than those in the control group by month 2 . This difference increased at 3 months $(350.1 \pm 16.4 \mathrm{~g}$ vs. $322.3 \pm 21.3 \mathrm{~g} \mathrm{p}=0.006)$ and 4 months $(374.4 \pm 22.2 \mathrm{~g}$ vs. $340.2 \pm 25.2 \mathrm{~g} \mathrm{p}=0.006)$ (Figure 1). At the end of the experiment, weights of the perinephric fat pads were significantly increased in the chlorpyrifos group relative to controls $(2.867 \pm 0.516$ vs. $1.130 \pm 0.171$, $\mathrm{p}=0.0039$, mean difference $=-1.737,95 \%$ confidence interval of the difference of the means $-2.835,-0.638)$. Heart weights were $1.456 \pm 0.240$ vs. $1.200 \pm 0.359$, with $\mathrm{p}=0.0859$. Liver weights were $4.444 \pm 1.657$ vs. $3.590 \pm 0.415$, $p=0.1322$, mean difference $=-0.845,95 \%$ confidence interval of the mean difference $=-1.994$ to 0.286 . These results are depicted in Figure 2 .

When pre-differentiated adipocytes were treated in culture with up to $.008 \mathrm{ug} / \mathrm{ml}$ of chlorpyrifos or with $10 \mathrm{ul} \mathrm{DMSO}$, normal cell growth was observed, with evident fat accumulation, but without acceleration of growth or increased numbers of cells. The chlorpyrifos treatment did result in an increased number of dead cells compared to the MDI-treated group.

\section{DISCUSSION}

The adverse health effects of obesity are enormous. Obese children are more likely to have increased risk factors for cardiovascular diseases, including elevations of blood pressure, cholesterol, lipids, and C-reactive protein [8,9]. Type 2 diabetes mellitus is also increased in obese children, and an association exists between childhood obesity and asthma with body mass index being a significant predictor of childhood asthma [10-12]. Fatty liver and cholecystitis are of increased incidence and prevalence in obese children $[13,14]$.

A possible cause contributing to the obesity epidemic is the introduction of chemicals with biological activity into the environment. These chemicals may result in obesity in susceptible individuals. Arguments to support this hypothesis include the rapidity with which obesity rates are increasing and the fact that environmental chemicals can act as 'endocrine disrupters' $[15,16]$. Pesticides may be one of these environmental chemicals. Organochlorine, organophosphate, and carbamate pesticides have been shown to have endocrine effects that can result in weight gain [17-23]. The World Health Organization states "there is no segment of the general population that is sheltered from exposure to pesticides and potentially serious health effects." Exposures may come in the form of residues on foods, pesticide drift, and insecticide treatment of houses, schools, and yards. The role of environmental chemicals in the epidemic of childhood and adolescent obesity has not been explored.

There is no doubt that human populations of the United States are chronically exposed to a host of environmental chemicals and have blood levels that indicate such levels. The Environmental Health Laboratory at the Centers for Disease Control has conducted laboratory investigations of blood and urine levels in human populations of the United States for a host of environmental chemicals. These investigations have established population-wide levels of organophosphate, carbamate, and pyrethroid insecticides, herbicides, as well as phthalates, 


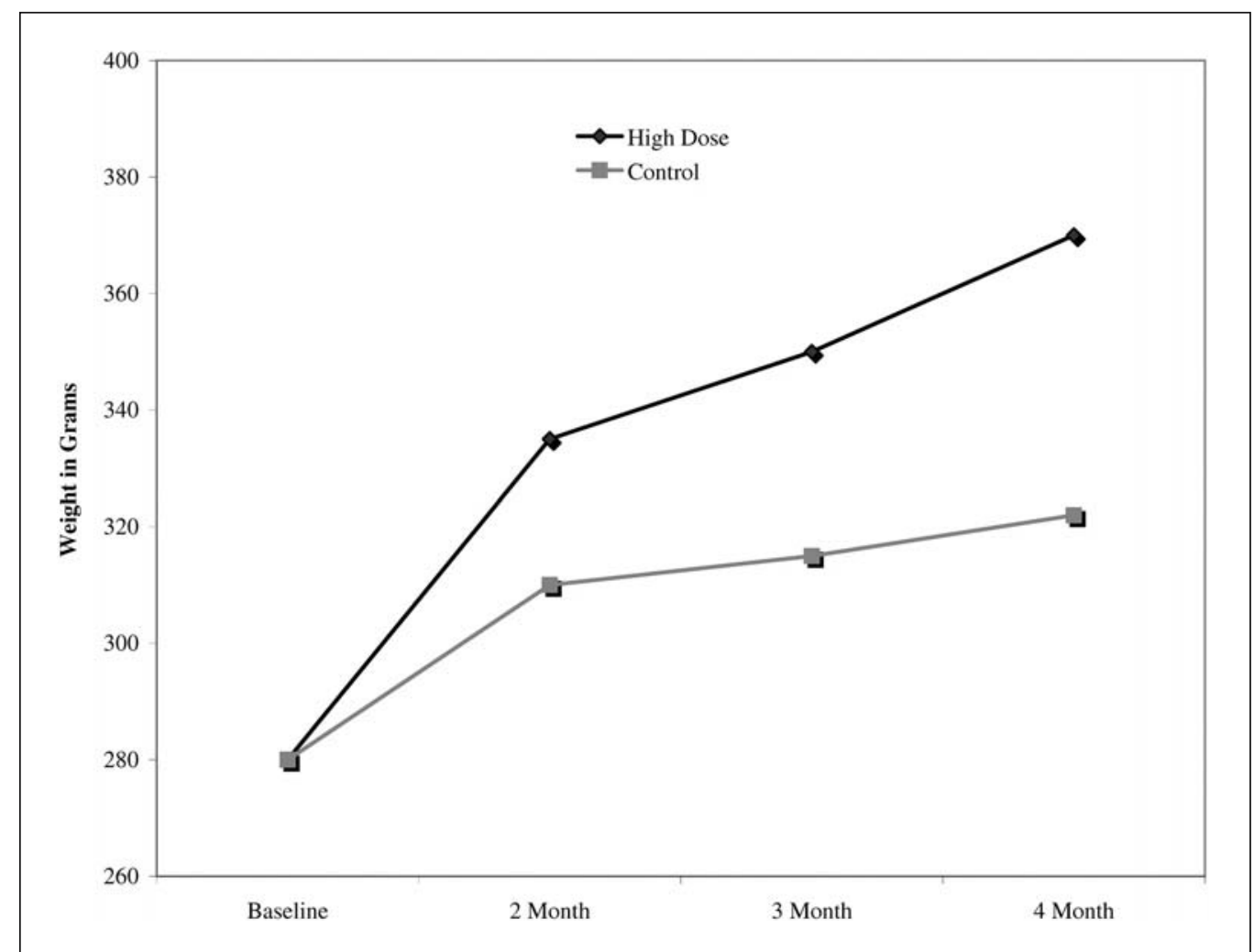

Figure 1: A Comparison of Total Body Weights in Grams of Rats Exposed to Chlorpyrifos $5 \mathrm{mg} / \mathrm{kg} / \mathrm{day}$ to Control Rats

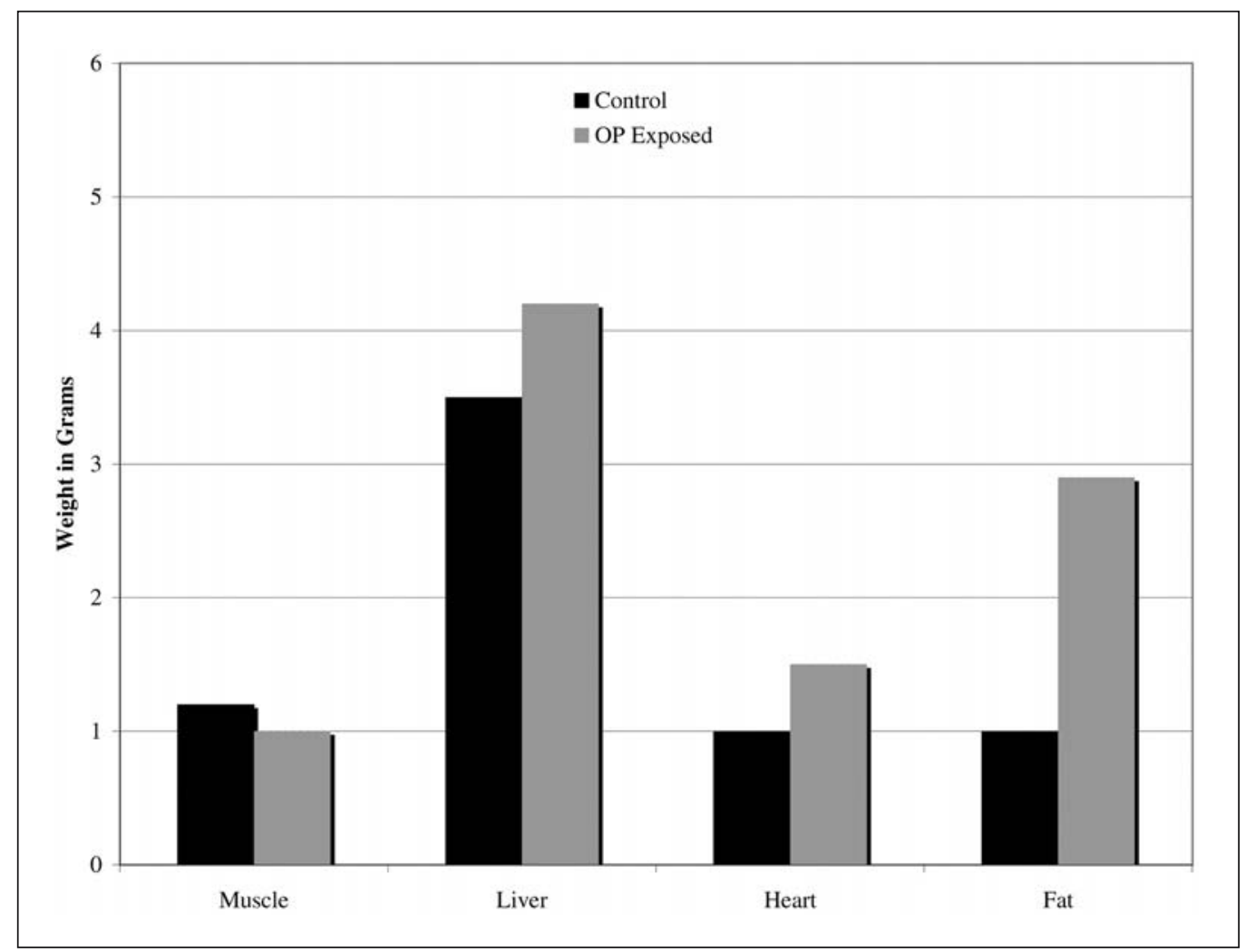

Figure 2: A Comparison of Gastrocnemius Muscle, Heart, Medial Lobe of Liver, and Peri-nephric Fat Pad Weights in Grams of Rats Exposed to Chlorpyrifos $5 \mathrm{mg} / \mathrm{kg} /$ day to Control Rats 
polyaromatic hydrocarbons, polychlorinated biphenyls, phytoestrogens, and heavy metals [4]. Any of these substances are possible candidates for playing a role in the obesity epidemic.

Organophosphate insecticides have a variety of actions beyond acute cholinergic toxicity that leads to autonomic hyperactivity and muscle weakness. This pilot study of long-term exposure to an organophosphate insecticide in young rats revealed a progressive increase in weight in those rats exposed to $5 \mathrm{mg} / \mathrm{kg} /$ day of chlorpyrifos, but not in the control group. Peri-nephric fat pad weight is used as a marker of total body fat. There was a significant increase in the weight of the peri-nephric fat pad but not in muscle, heart, or liver. The weight increase represents an increase in adipose tissue. Rats did not have any evidence of acute toxic effects during the course of the experiment.

Organophosphate pesticides may induce accelerated differentiation of immature adipocytes into mature fat cells. This is one potential mechanism of weight gain. When this theory was tested in culture, it was not substantiated. When pre-differentiated adipocytes were treated with a dose of clorpyrifos that was not toxic to the cells, the number of cells that differentiated from the controls was not noticeable.

\section{LIMITATIONS}

The specific mechanism for weight gain in exposed animals is not elucidated. This will be a direction for future research. Possible mechanisms that need further examination include endocrine and metabolic effects. Other investigators have shown that organophosphates are capable of inducing hypothyroidism and euthyroid syndrome, both states that would result in abnormal weight gain [7]. The sample size is small, but it was large enough to obtain a statistically significant result.

Further investigations are also needed to determine if the result seen with chlorpyrifos generalizes to other insecticides, other classes of environmental chemicals, other age groups, and other species. Generalizations to humans cannot be made at this time. But with a remarkable increase in obesity in human populations chronically exposed to environmental chemicals, this area of study becomes an important one in terms of potential impact on human health.

The authors have no potential financial conflicts of interest to report.

\section{REFERENCES}

1. Hedley AA, Ogden CL, Johnson CL, et al. Prevalence of overweight and obesity among US children, adolescents, and adults, 1999-2002. JAMA 2004;291(23):2847-50.

2. Wang Y. Cross-national comparison of childhood obesity: the epidemic and the relationship between obesity and socioeconomic status. International Journal of Epidemiology

2005;30(5):1129-36.
3. Baillie-Hamilton PF. Chemical toxins: a hypothesis to explain the global obesity epidemic. J Altern Complement Med 2002;8(2):185-92.

4. Centers for Diseases Control. Third national report on human exposure to environmental chemicals. National Center for Environmental Health report NCEH No. 050570, Atlanta, July 2005.

5. Roldan-Tapia L, Parron T, Sanchez-Santed F: Neuropsychological effects of long-term exposure to organophosphate pesticides. Neurotoxicol Teratol 2005;27(2):259-266.

6. Satar S, Sebe, Topal M, Karacioglu O: Endocrine effects of acute organophosphate antidotal therapy. Adv Ther 2004;21(5):301-311.

7. Satar S, Satar D, Kirim S, Leventerler H: Effects of acute organophosphate poisoning on thyroid hormones in rats. Am J Ther 2005; 12(3):238-242.

8. Freedman DS, Dietz WH, Srinvivasan SR, Berenson GS. The relation of overweight to cardiovascular risk factors among children and adolescents: the Bogalusa Heart Study. Pediatrics 1999; 103(6 Pt 1):1175-82.

9. Ford ES, Galuska DA, Gillespie C, Will JC, Giles WJ, Dietz WH. C-reactive protein and body mass index in children: findings from the Third National Health and Nutrition Examination Survey, 1988-1994. J Pediatr 2001;138(4):486-92.

10. American Diabetic Association. Type 2 diabetes in children and adolescence. Pediatrics 2000;105(3Pt1):671-680.

11. Ford ES. The epidemiology of obesity and asthma. J Allergy Clin Immunol 2005;115(5):897-909

12. Saha C, Riner ME, Liu G. Individual and neighborhoodlevel factors in predicting asthma. Arch Pediatr Adolesc Med 2005; 159(8):759-63.

13. Kinugasa A, Tsunamoto K, Furukawa N, Sawada T, Kusunoki T, Shimada N. Fatty liver and its fibrous changes found in simple obesity of children. J Pediatr Gastroenterol Nutr 1984;3(3):408-14.

14. Crichlow RW, Seltzer MH, Jannetta PJ. Cholecystitis in adolescence. Am J Dig Dis 1972;(1):68-72.

15. Anonymous. Overweight and Obesity: Obesity Trends: U.S. Obesity Trends 1985-2005. Behavrioal Risk Factor Surveillance system. Centers for disease Control. Available From: http://www.cdc.gov/nccdphp/dnpa/obesity/trends/ maps/index.htm.

16. Tabb MM. Blumberg B. New modes of action for endocrine-disrupting chemicals. Molecular Endocrinology. 2006; 20 :475-82.

17. Chadwick RS, Cooper RL, Chang J. Possible antiestrogenic activity of lindane in female rats. J Biochem Toxicol 1988 Fall;3:147-58.

18. Cranmer JS, Avery DL, Grady RR, Kitay JI. Postnatal endocrine dysfunction resulting from prenatal exposure to carbofuran, diazinon or chlordane. J Environ Pathol Toxicol 1978;2(2):357-69.

19. Nicolau GY. Circadian rhythms of RNA, DNA and protein in the rat thyroid, adrenal and testis, in chronic pesticide 
exposure. IV. Effects of the herbicide 2,4-dichlorophenoxyacetic acid. Endocrinologie 1983;21(3):169-74.

20. Rumsey TS, Tao H, Bitman J. Effects of ronnel on growth, endocrine function and blood measurements in steers and rats. J Anim Sci 1981;53(1):217-25.

21. Trankina ML, Beitz DC, Trenkle AH. Effects of in vitro ronnel on metabolic activity in subcutaneous adipose tissue and skeletal muscle from steers. J Anim Sci 1985;60(3):652-8.
22. Walker EM, Fazekas-May MA, Heard KW, Yee S, Montague D, Jones MM. Prevention of cisplatin-induced toxicity by selected dithiocarbamates. Ann Clin Lab Sci 1994;24(2):121-33.

23. Yen JT, Nienaber JA, Pond WG, Varel VH. Effect of carbadox on growth, fasting metabolism, thyroid function and gastrointestinal tract in young pigs. J Nutr. 1985 Aug;115(8): 970-9. 